\title{
Residue level and health risk assessment of organophosphorus pesticides in country bean and bitter gourd collected from Cumilla, Bangladesh
}

\author{
${ }^{1}$ Rahman, A., ${ }^{1}$ Kaium, A., ${ }^{1}$ Khan, M.S.I., ${ }^{1}$ Islam, M.A., ${ }^{1}$ Begum, N., ${ }^{2}$ Prodhan, M.D.H., \\ ${ }^{1}$ Hossain, A., ${ }^{3}$ Mustafiz, S.S.B. and ${ }^{1,{ }^{*}}$ Chowdhury, M.T.I. \\ ${ }^{1}$ Department of Agricultural Chemistry, Sher-e-Bangla Agricultural University, Dhaka, Bangladesh. \\ ${ }^{2}$ Pesticide Research and Environmental Toxicology Section, Entomology Division, Bangladesh \\ Agricultural Research Institute, Gazipur, Bangladesh. \\ ${ }^{3}$ Bangladesh Sugar and Food Industries Corporation, Motijheel, Dhaka, Bangladesh
}

\author{
Article history: \\ Received: 8 February 2021 \\ Received in revised form: 13 \\ March 2021 \\ Accepted: 16 May 2021 \\ Available Online: 19 \\ December 2021
}

Keywords:

Pesticide residues,

Vegetables,

Risk assessment,

QuEChERS

DOI:

https://doi.org/10.26656/fr.2017.5(6).041

\begin{abstract}
Organophosphorus pesticides are one of the most commonly used pesticide classes in agriculture in the management of insect pests due to their high efficacy. The extensive use of organophosphorus pesticides can contaminate both the atmosphere and food, which may lead to health problems. In this study, the residue level of organophosphorus pesticides, and their health risk assessment was evaluated on country bean and bitter gourd. Out of forty analysed samples of the country bean, two samples contained multiple residues, seven samples contained single residue. On the other hand, out of forty samples of bitter gourd, one sample contained multiple residues and three samples contained single residue. Among the organophosphorus pesticides, diazinon was the most frequently detected organophosphorus pesticide in country bean and bitter gourd. The highest short-term risks or acute risk (aHI) was below 1.83\%, and the highest long-term risk or chronic risk (HQs) was below $10.46 \%$ for the country bean and bitter gourd, respectively. Short- and long-term risk assessment results showed that the intake risks of country bean and bitter gourd were acceptable. The health hazard results showed that country bean and bitter gourd consumption in Cumilla, Bangladesh does not pose an acute or chronic risk to human health. However, a routine monitoring system must be established to control the contamination of vegetables with pesticides.
\end{abstract}

\section{Introduction}

Organophosphorus pesticides (OPPs) are organic derivatives of phosphoric acid, phosphonic acid, phosphorothioic acid, or phosphonothioic acids (Corbett, 1974; Gupta, 2005; Espinoza et al., 2017; Eto and Zweing, 2018). In 1937, Schrader and his colleagues found contact insecticidal activity in certain organophosphorus compounds (Ramulu, 2020). Still, organophosphorus pesticides are one of the most commonly used pesticide classes in agriculture in the management of insect pests due to their high efficacy, comparatively high dissipation and low persistence compared to other pest class pesticides (González et al., 2012; Eto and Zweig, 2018). More often, pesticides are misused, including overdoses, adulterated formulas, and harvesting without a minimum waiting period (HerreraHerrera et al., 2019). The extensive use of pesticides can contaminate both the atmosphere and food, which may lead to health problems (Sultana and Nakagoshi, 2001;
Islam et al., 2009). In the case of OPPs, extensive exposure to higher concentrations can lead to cardiovascular, nervous, respiratory, metabolic, reproductive and even immune symptoms problems (Bello-Ramírez et al., 2000; Kwong, 2002; Joshi and Sharma, 2011). Besides, these groups of compounds are likely to change embryonic health and lead in children to ADHD (Hassani et al., 2017). The toxicity of OPPs metabolites is much more toxic than the parent compound itself. Thus, OPPs are known to be the most toxic class of pesticides in insects, animals and humans (Hassani et al., 2017). According to the USA pesticide usage database, the most frequently used OPPs are malathion, dimethoate, chlorpyrifos, acephate, naled, diazinon, methyl-parathion, dicrotophos, phorate, phosmet, and azinphos-methyl (Grube et al., 2011). In the developing world, pesticide selection is mostly older, broad-spectrum, organophosphate and carbamate class, because of their acute toxicity and cheaper than the 
newer types (Sultana and Nakagoshi, 2001).

Bangladesh is a land of agriculture, and many farmers cultivate vegetables in their home garden and the field on a commercial basis (Chowdhury et al., 2011). Bitter gourd and country bean are major vegetables that are grown extensively in some particular growing areas in Bangladesh like Cumilla, Bogra, Jessore and Narsingdi (Rahaman et al., 2008; Rahaman et al., 2016). In the context of Bangladesh, farmers have frequently used pesticides to ensure the quality and higher yields of vegetables (Dasgupta et al., 2007; Hossain et al., 2015). The most alarming concern is that Farmers of Bangladesh often spray hazardous pesticides like OPPs up to five to six times than the recommended dosage in one crop growing season (Sultana and Nakagoshi, 2001; Dasgupta et al., 2007; Hossain et al., 2015). In recent years, bitter gourd and country bean cultivation have become expensive and risky for farmers and consumers due to the increased use of chemical pesticides to control pests (Akram et al., 2010). Also, in most areas of Bangladesh, vegetables are marketed without maintaining a pre-harvest interval period. These market vegetables often contain pesticide residues due to overuse in the farm, which has adverse effects on human health (Dasgupta et al., 2007; Chowdhury et al., 2011). A study found pesticide residues in bitter gourds next to brinjal, which is the reason for the vegetable export reduction (Quasem, 2003). In order to ensure consumer safety, most countries have established a maximum residue limit (MRL) and an acceptable daily intake (ADI) of pesticide residues in food items (Chowdhury et al., 2011). The impact of daily intakes of pesticide residues in food should be measured by an exposure or risk assessment.

In the present study, seven mostly used organophosphorus pesticides (acephate, chlorpyrifos, diazinon, dimethoate, fenitrothion, malathion and quinalphos) were selected to determine the level of residues in country bean and bitter gourd marketed in Cumilla, Bangladesh. This study also aimed to assess the short-term and long long-term health risks to consumers posed by these pesticide residues on country bean and bitter gourd.

\section{Materials and methods}

\subsection{Chemicals}

The standard $(>99.6 \%$ pure $)$ of acephate, chlorpyrifos, diazinon, dimethoate, fenitrothion, malathion and quinalphos were purchased from SigmaAldrich (St Louis, MO, USA) via Bangladesh Scientific Pvt. Ltd. Dhaka, Bangladesh. Analytical grade methanol, acetone, HPLC grade acetonitrile, sodium chloride
$(\mathrm{NaCl})$, anhydrous magnesium sulphate $\left(\mathrm{MgSO}_{4}\right)$ and Primary Secondary Amine (PSA) were purchased from Bangladesh Scientific Pvt. Ltd.

\subsection{Study area}

The study area included five major markets in the Cumilla district (Figure 1). It is a district of Bangladesh situated approximately 100 kilometres southeast of Dhaka. This study was conducted by collecting country beans and bitter gourds for pesticide residues from several Upazilla markets in Cumilla District. The central markets of Chandina, Debidwar and Daudkandi Upazilla and Kangshanagar Bazar under Burichang Upazilla and Maynamati Bazar under Cumilla Sadar Upazilla were considered for sample selection. These markets are famous for vegetables and vegetables are grown in various areas in the Cumilla district and certain parts of the neighbour areas.

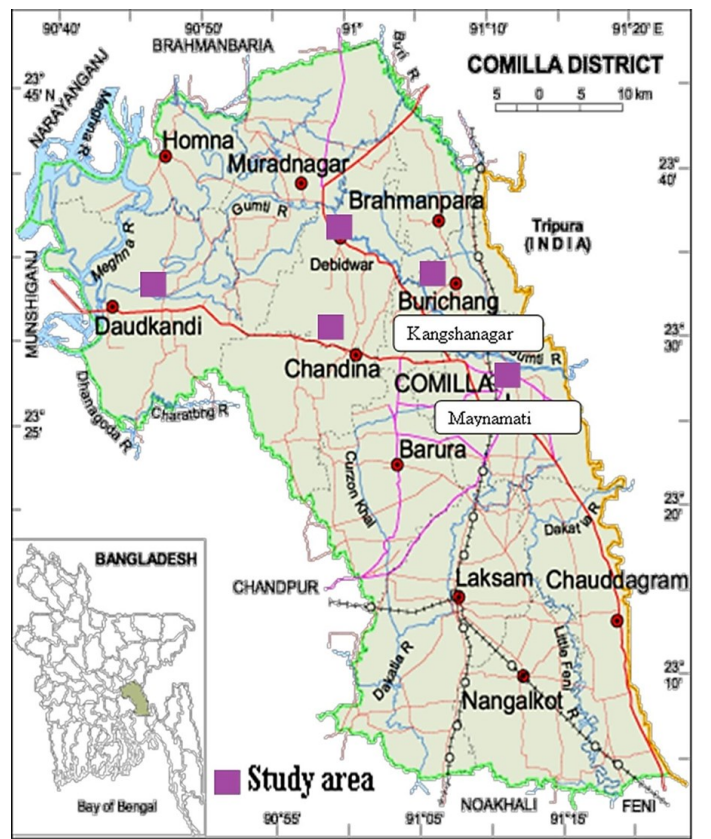

Figure 1. Map showing the places of sample collection in Cumilla district

\subsection{Sample collection}

For this research, 80 samples were collected (40 country beans and 40 bitter gourds). Eight country bean samples and eight bitter gourd samples were collected from each market (Chandina, Debidwar, Daudkandi, Kangshanagar and Maynamati) in the district of Cumilla. For the selected vegetables, each sample amounted to $1 \mathrm{~kg}$. The samples were collected in individual polythene bags, and each bag has been appropriately labelled with the sample numbers and sources. The collected samples were transported on collection day to the Pesticide Analytical Laboratory of Bangladesh Agricultural Research Institute (BARI), Gazipur. Each sample was cut into small pieces and appropriately mixed for homogeneity. 
Then, the chopped samples were processed at $-20^{\circ} \mathrm{C}$ using airtight zipper bags before the extraction and clean -up process started.

\subsection{Preparation of pesticide standard solution}

Pesticide standard stock solutions of acephate, chlorpyrifos, diazinon, dimethoate, fenitrothion, malathion and quinalphos were prepared separately in acetone at a concentration of $1000 \mathrm{mg} / \mathrm{L}$ and stored at $20^{\circ} \mathrm{C}$ until use. A mixed standard solution of $50 \mathrm{mg} / \mathrm{L}$ in acetone containing all the pesticides as mentioned above was prepared by adding the appropriate volume of each stock solution in a $50 \mathrm{ml}$ volumetric flask and made to the volume by addition of acetone. An intermediate mixed standard solution of $10 \mathrm{mg} / \mathrm{L}$ in acetone was prepared from the mixed standard solution of $50 \mathrm{mg} / \mathrm{L}$. Then working standard solutions of $0.1,0.2,0.5,1.0,2.0$, 3.0 , and $5.0 \mathrm{mg} / \mathrm{L}$ in acetone were prepared by transferring the appropriate amount from $10 \mathrm{mg} / \mathrm{L}$ intermediate mixed standard solution into ten separate 10 $\mathrm{mL}$ volumetric flasks. All the standard solutions were kept in a freezer at $-20^{\circ} \mathrm{C}$ until use.

\subsection{Extraction and clean-up}

In this study, the modified QuEChERS extraction technique was used for the extraction and clean-up of the collected vegetable samples (Prodhan et al., 2015). The chopped vegetable samples were grounded thoroughly with a blender. A representative $10 \mathrm{~g}$ portion of the thoroughly homogenized sample was weighted in a 50 $\mathrm{mL}$ polypropylene centrifuge tube. Then $10 \mathrm{~mL}$ of acetonitrile $(\mathrm{MeCN})$ was added into the centrifuge tube. The centrifuge tube was appropriately closed and shaken vigorously for $30 \mathrm{~s}$ by the use of a vortex mixer. Then, 4 $\mathrm{g}$ of anhydrous $\mathrm{MgSO}_{4}$ and $1 \mathrm{~g}$ of $\mathrm{NaCl}$ were added into the centrifuge tube, and it was shaken immediately by the vortex mixer for $1 \mathrm{~min}$ to prevent the formation of magnesium sulfate aggregates. Afterwards, the extract was centrifuged for $5 \mathrm{mins}$ at $5000 \mathrm{rpm}$. An aliquot of 3 $\mathrm{mL}$ of the MeCN layer was transferred into a $15 \mathrm{~mL}$ centrifuge tube containing $600 \mathrm{mg}$ anhydrous $\mathrm{MgSO}_{4}$ and $120 \mathrm{mg}$ Primary Secondary Amine (PSA). Then it was thoroughly mixed by vortex for $30 \mathrm{~s}$ and centrifuged for 5 mins at $4000 \mathrm{rpm}$ (Laboratory Centrifuges, Sigma3K30, Germany). After centrifuge, a $1 \mathrm{~mL}$ supernatant was filtered by a $0.2 \mu \mathrm{m}$ PTFE filter, and then it was taken in a clean GC vial for further analysis.

\subsection{Instrumental analysis}

The concentrated extracts were subjected to analysis by GC-2010 (Shimadzu) with Flame Thermionic Detector (FTD) for the detection of OPPs. The capillary column was AT-1 $(30 \mathrm{~m} \times 0.25 \mathrm{~mm} \times 0.25 \mu \mathrm{m})$ was used to separate the analytes. The split mode was used for injection, and the injector and detector temperature were $250^{\circ} \mathrm{C}$ and $280^{\circ} \mathrm{C}$ with a split ratio: $30: 0$. The column temperature was programmed as follows: from $150^{\circ} \mathrm{C}$ for $1 \mathrm{~min}$, from 150 to $220^{\circ} \mathrm{C}$ for 2 mins at $10^{\circ} \mathrm{C} /$ min. Helium was used as the carrier at a flow rate of 1.5 $\mathrm{mL} / \mathrm{min}$, and as a make-up gas at a flow rate of $30 \mathrm{~mL} /$ min for FTD with airflow at $145 \mathrm{~mL} / \mathrm{min}$. The flow rates of Helium and air were adjusted at $1.00 \mathrm{~Pa}$, with a total run time was 10 mins.

\subsection{Quality assurance procedure}

The experiment was validated on parameters of specificity, linearity, determination coefficient $\left(\mathrm{R}^{2}\right)$ and limit of quantification (LOQ). The specificity was determined by specific retention time on the chromatogram for specific pesticides. The linearity and determination co-efficient was calculated continuously by standard fortified solutions of each pesticide at 0.05 to $0.5 \mathrm{mg} / \mathrm{kg}$ concentration levels. The limit of quantification was calculated as the lowest detection level for each pesticide. The limit of quantification (LOQ) was used to measure the sensitivity of the method.

\subsection{Health risk assessment}

The acute health risk to consumer (aHI) was measured using the estimated short-term intake (ESTI) and the acute reference dose (ARfD). The chronic health risk/hazard quotient (HQ) to consumers was measured using the estimated daily intake (EDI) and the acceptable daily intake (ADI). The hazard quotient indicates a potential risk if it reaches $100 \%$ and the higher aHI/HQ value is the higher risk. For the appropriate calculation, the ARfD and ADI values expressed as an $\mathrm{mg} / \mathrm{kg}$ of daily intake for a $60 \mathrm{~kg}$ person for seven organophosphorus pesticides were obtained from the Joint FAO/WHO Meeting on Pesticide Residues (JMPR) database (http://apps.who.int/pesticide-residues-jmprdatabase) (JMPR, 2004; JMPR, 2006). According to $\mathrm{FAO} / \mathrm{WHO}$, the average national per capita consumption of $23 \mathrm{~g}$ of leafy vegetables, $89 \mathrm{~g}$ of non-leafy vegetables and $14 \mathrm{~g}$ of fruit is an average of $126 \mathrm{~g}$ of fruit and vegetables per day in Bangladesh (FAO/WHO, 2003; Monoarul Haque et al., 2014). The equation for calculation of ESTI, aHI, HQ and cHI were given below:

ESTI $=$ the highest residue level $\times$ food consumption/ body weight

$\mathrm{aHI}=\mathrm{ESTI} / \mathrm{ARfD} \times 100 \%$

EDI $=$ mean residue level $\times$ food consumption/body weight

$\mathrm{HQ}=\mathrm{EDI} / \mathrm{ADI} \times 100 \%$ 


\subsection{Statistical analysis}

The level of pesticide residue in collected samples was analysed and calculated in $\mathrm{mg} / \mathrm{kg}$ automatically by the Shimadzu GC software. All the data analysis and calculations were made by MS Excel 2013 software.

\section{Results and discussion}

\subsection{Validation of the method}

The linearity, determination coefficient $\left(\mathrm{R}^{2}\right)$, and LOQ were measured in external standard solution by using the peak areas obtained by GC-FTD analysis. The linear regression equation and determination coefficient $\mathrm{R}^{2}$ values and LOQ were given in Table 1 . The standard curve results showed that the linearity is excellent, with a determination coefficient of $\mathrm{R}^{2}$ value higher than 0.9945 . The limits of quantification (LOQs) were $0.01 \mathrm{mg} / \mathrm{L}$, indicating the high sensitivity of this method. The proposed method was applied to the external standard solution for assessing its specificity. The specificity of seven selected organophosphorus pesticides was performed by comparing the retention times of each pesticide presented in a typical chromatogram obtained by GC-FTD using analysis of external added standard solution and matrix solvent (Figure 2).

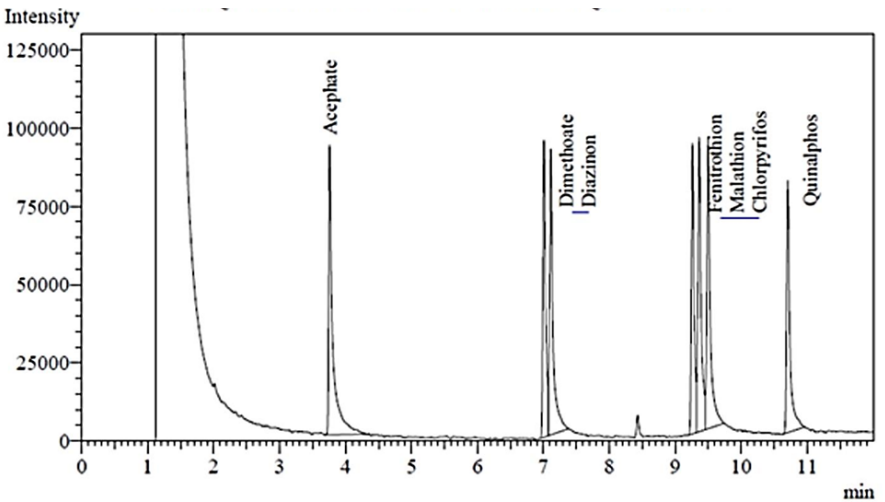

Figure 2. GC-FTD chromatogram of seven organophosphorus pesticides in external added standard spiked at $0.1 \mathrm{mg} / \mathrm{kg}$

\subsection{Pesticide residues in country bean}

Out of forty samples of the country bean, nine samples $(22.50 \%$ of the total number of samples) contained diazinon residue and two samples $(5 \%$ of the total number of samples) contained dimethoate residue (Table 2). In the country bean, the most frequently detected pesticide was diazinon $(22.50 \%)$, followed by dimethoate (5\%). Among the seven OPPs, acephate, chlorpyrifos, fenitrothion, malathion and quinalphos were not detected in any country bean samples were collected from five major vegetable markets of Cumilla district. These findings were very similar to Islam et al. (2014). They analysed 42 brinjals, cauliflower and country bean samples from the field and markets of the Narsingdi district where 15 samples were not detected any OPPs (Islam et al., 2014). The study findings were well agreed with Hasan et al. (2017). In country bean samples collected from different markets of Dhaka, they have detected two kinds of insecticides (such as dimethoate and quinalphos). Out of 50 analysed country bean samples, ten samples (20\%) contained dimethoate and quinalphos residues, 5 of which exceeded the maximum residue limits (MRLs). Most contaminated samples (8 samples) contained dimethoate residue (Hasan et al., 2017). Ahmed et al., (2017) analysed 170 samples collected from Jessore, Cumilla, Narsingdi, Tangail, Rangpur, Jamalpur, Gazipur and Dhaka for residue analysis in brinjal, yard long bean, bitter gourd, snake gourd, pointed gourd, okra, tomato, hyacinth bean and cabbage samples. Among the 170 samples, $21.78 \%$ were contaminated with insecticides, either single or multiple residues, in which $18.26 \%$ of samples had residues above MRL (Ahmed et al., 2017).

According to Figure 3, diazinon was the most frequently detected pesticide followed by dimethoate in the country bean samples collected from 5 major vegetable markets (Chandina, Debidwar, Daudkandi, Kangshanagar and Maynamati) of Cumilla district of Bangladesh.

\subsection{Pesticide residues in bitter gourd}

Out of forty samples of bitter gourd, three samples $(7.50 \%$ of the total number of samples) contained diazinon residue, one sample $(2.50 \%$ of the total number of samples) contained multiple residues (Table 3) which

Table 1. Linear regression parameters and LOQ of the seven selected organophosphorus pesticides in the external added standard solution

\begin{tabular}{ccccc}
\hline Name of pesticide & Concentration $(\mathrm{mg} / \mathrm{kg})$ & Linear equation & $\mathrm{R}^{2}$ & LOQ $(\mathrm{mg} / \mathrm{kg})$ \\
\hline Acephate & $0.05-0.5$ & $\mathrm{y}=64654 \mathrm{x}+294.93$ & 0.9995 & 0.01 \\
Chlorpyrifos & $0.05-0.5$ & $\mathrm{y}=61270 \mathrm{x}+553.08$ & 0.9994 & 0.01 \\
Diazinon & $0.05-0.5$ & $\mathrm{y}=113063 \mathrm{x}+882.86$ & 0.9945 & 0.01 \\
Dimethoate & $0.05-0.5$ & $\mathrm{y}=44867 \mathrm{x}+716.55$ & 0.999 & 0.01 \\
Fenitrothion & $0.05-0.5$ & $\mathrm{y}=100414 \mathrm{x}+977.86$ & 0.9975 & 0.01 \\
Malathion & $0.05-0.5$ & $\mathrm{y}=41036 \mathrm{x}+340.41$ & 0.9945 & 0.01 \\
Quinalphos & $0.05-0.5$ & $\mathrm{y}=81217 \mathrm{x}+211.14$ & 0.9993 & 0.01 \\
\hline $\mathrm{R}^{2}=$ linear determination coefficient & & &
\end{tabular}


Table 2. Summary of pesticide residue analysis in the country bean

\begin{tabular}{|c|c|c|c|c|c|c|c|c|}
\hline \multirow{2}{*}{ Vegetable } & \multirow{2}{*}{ Pesticide } & \multicolumn{2}{|c|}{ No of the sample } & \multirow{2}{*}{$\begin{array}{c}\text { Detected } \\
\text { samples }(\%)\end{array}$} & \multirow{2}{*}{$\begin{array}{l}\mathrm{MRL}^{*} \\
(\mathrm{mg} / \mathrm{kg})\end{array}$} & \multirow{2}{*}{$\begin{array}{l}\text { No of samples } \\
>\text { MRL }(\mathrm{mg} / \mathrm{kg})\end{array}$} & \multirow{2}{*}{$\begin{array}{l}\text { Residual Range } \\
(\mathrm{mg} / \mathrm{kg})\end{array}$} & \multirow{2}{*}{$\begin{array}{l}\text { Mean residue } \\
(\mathrm{mg} / \mathrm{kg})\end{array}$} \\
\hline & & Analysed & Detected & & & & & \\
\hline \multirow[t]{7}{*}{ Country bean } & Acephate & 40 & 0 & & 0.01 & & & \\
\hline & Chlorpyrifos & 40 & 0 & & 0.01 & & & \\
\hline & Diazinon & 40 & 9 & 22.50 & 0.01 & 9 & $0.079-0.138$ & 0.1067 \\
\hline & Dimethoate & 40 & 2 & 5 & 0.01 & 2 & $0.034-0.247$ & 0.1405 \\
\hline & Fenitrothion & 40 & 0 & & 0.01 & & & \\
\hline & Malathion & 40 & 0 & & 0.02 & & & \\
\hline & Quinalphos & 40 & 0 & & 0.01 & & & \\
\hline
\end{tabular}

*According to the EU Pesticide Database (EC-396/2005) (European Commission, 2005)

Table 3. Summary of pesticide residue analysis in bitter gourd

\begin{tabular}{ccccccccc}
\hline Vegetable & Pesticide & \multicolumn{2}{c}{ No of the sample } & \begin{tabular}{c} 
Detected \\
\cline { 3 - 4 } samples $(\%)$
\end{tabular} & $\begin{array}{c}\text { MRL* } \\
(\mathrm{mg} / \mathrm{kg})\end{array}$ & $\begin{array}{c}\text { No of samples } \\
\text { >MRL }(\mathrm{mg} / \mathrm{kg})\end{array}$ & $\begin{array}{c}\text { Residual Range } \\
(\mathrm{mg} / \mathrm{kg})\end{array}$ & $\begin{array}{c}\text { Mean residue } \\
(\mathrm{mg} / \mathrm{kg})\end{array}$ \\
\hline Bitter gourd & Acephate & 40 & & & 0.01 & & 0.056 & 0.056 \\
& Chlorpyrifos & 40 & 1 & 2.50 & 0.01 & 1 & $0.086-0.113$ & 0.097 \\
& Diazinon & 40 & 3 & 7.50 & 0.01 & 3 & 0.032 & 0.032 \\
& Dimethoate & 40 & 1 & 2.50 & 0.01 & 1 & & \\
& Fenitrothion & 40 & & & 0.01 & & \\
& Malathion & 40 & & & 0.02 & & \\
& Quinalphos & 40 & & & 0.01 & & \\
\hline
\end{tabular}

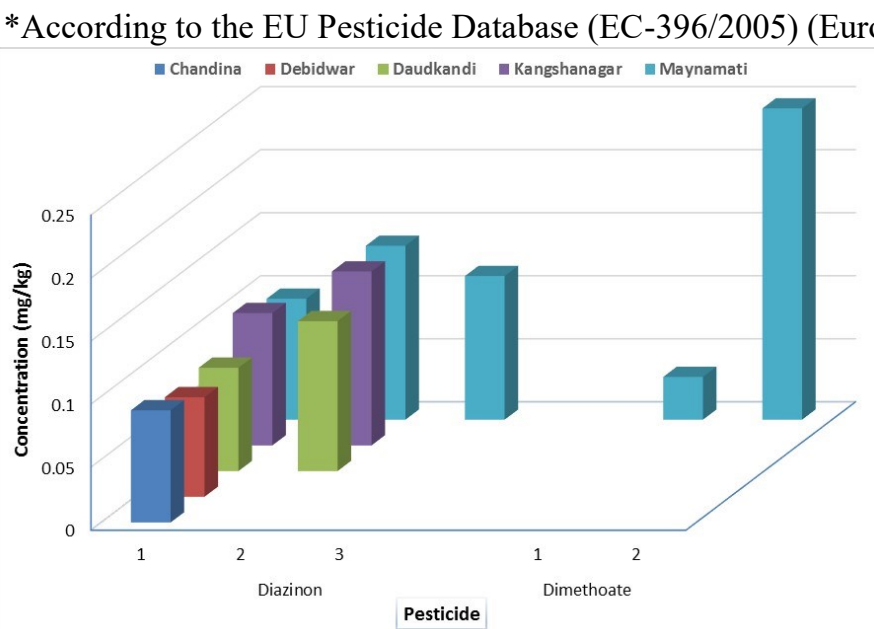

Figure 3. Frequency of organophosphorus pesticide residues with the amount in the country bean collected from different markets of Cumilla, Bangladesh

were above the European Union maximum residue limit (EU-MRLs). In the bitter gourd, the most frequently detected pesticide was diazinon $(22.50 \%)$, followed by dimethoate $(5 \%)$. Among the seven OPPs, acephate, fenitrothion, malathion and quinalphos were not detected in any bitter gourd samples collected from five major vegetable markets of Cumilla district. The findings of this study can also be compared to Akter et al. (2017). They found $22 \%$ of samples contained pesticide residues of diazinon, dimethoate, quinalphos, and chlorpyrifos residues in brinjal collected from the Mymensingh district. Among the detected OPP residues, only five samples exceeded the MRL set by EU (Aktar et al., 2017). The present study is supported by Islam et al. (2019). They found that about $12 \%$ bitter gourd samples were contaminated with different organophosphorus pesticides (Islam et al., 2019).

Figure 4 shows diazinon was the most frequently detected pesticide followed by dimethoate and chlorpyrifos in bitter gourd samples collected from five major vegetable markets (Chandina, Debidwar, Daudkandi, Kangshanagar and Maynamati) of Cumilla district of Bangladesh. Out of 40 analysed bitter gourd samples only one bitter gourd sample collected from Kangshanagar vegetable market under Burichang Upazilla contained multiple residues of diazinon (0.093 $\mathrm{mg} / \mathrm{kg})$ and dimethoate $(0.032 \mathrm{mg} / \mathrm{kg})$. Another two bitter gourd samples collected from Debidwar and Daudkandi vegetables market contained a single residue of diazinon $(0.113$ and $0.086 \mathrm{mg} / \mathrm{kg})$. Only one bitter gourd sample contained chlorpyrifos residue $(0.056 \mathrm{mg} /$ $\mathrm{kg}$ ) collected from Maynamati Bazar under Cumilla

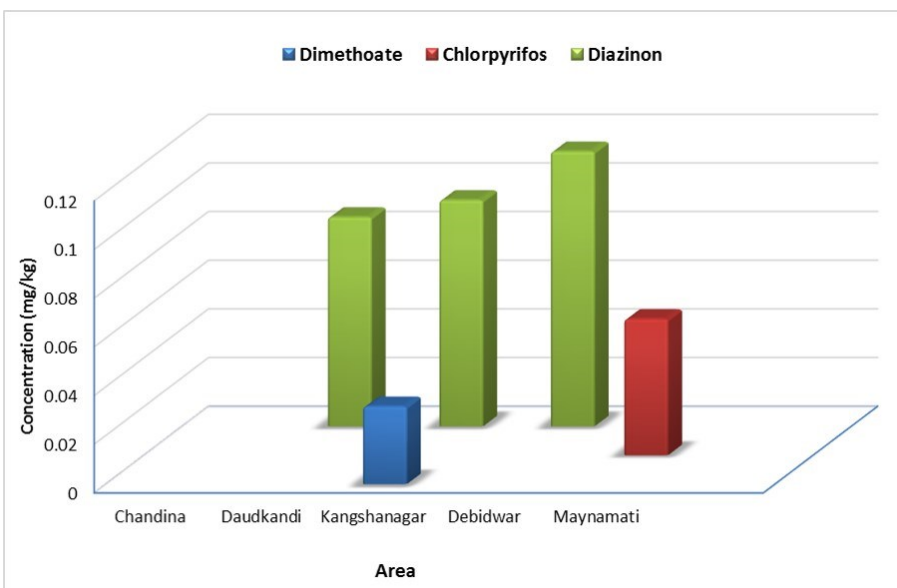

Figure 4. Frequency of organophosphorus pesticide residues with the amount in bitter gourd collected from different markets of Cumilla, Bangladesh 
Sadar Upazilla. Nevertheless, other thirty-six bitter gourd samples $(90 \%$ of the total number of samples) collected from these five major vegetable markets of Cumilla district contained no detectable residues of the sought pesticides.

\subsection{Risk assessment}

The mean concentrations of detected OPP pesticide residues were above their corresponding MRL levels (Table 2 and Table 3). The high-level residue in the country bean samples of some OPPs is an indicator of the recent use of diazinon and dimethoate on country bean farms. The OPPs health risk estimated in the country bean samples were represented in Table 4. For short-term risk analysis, all ESTI values were much lower than JMPR's ARfD values. Besides, the highest risk came from dimethoate with aHI w1.83\%, followed by diazinon with aHI $0.68 \%$. All the aHIs were lower than $100 \%$, which indicates there was a negligible shortterm or acute risk with the exposure to the tested pesticides via country bean consumption.
Moreover, in the long-term risk assessment, the risk quotient (HQs) was notably higher than acute risk indexes, which indicated the chronic risk from pesticide exposure via vegetable consumption should be considered. The long-term health risks (HQs) due to acephate, chlorpyrifos, diazinon, dimethoate, fenitrothion, malathion and quinalphos in the country bean was $0.025,0.074,3.174,10.458,0.148$ and 0.025 , respectively, suggesting that peoples in Cumilla have no significant health risk through the consumption of country bean since all the calculated values were less than $100 \%$. Nevertheless, dimethoate presented the highest health risk index. In consequence, neither of the organophosphorus pesticide residues present in the country bean posed a risk for human health

Table 4 and Table 5 contains the acute and chronic health risk values for acephate, chlorpyrifos, diazinon, dimethoate, fenitrothion, malathion and quinalphos in bitter gourd. For short-term risk assessment, all aHI values show much lower than $100 \%$. That means, there was a negligible short-term or acute risk with the

Table 4. The short-term and long-term risks due to the average daily intake of organophosphorus pesticides through country bean consumption in Cumilla, Bangladesh.

\begin{tabular}{lcccccc}
\hline \multirow{2}{*}{ Pesticide } & \multicolumn{3}{c}{ Short-term risk } & \multicolumn{3}{c}{ Long-term risk } \\
\cline { 2 - 7 } & ESTI (mg/kg/day) & ARfD (mg/kg/bw/day) & aHI (\%) & EDI (mg/kg/day) & ADI (mg/kg/day) & HQ \\
\hline Acephate & $7.42 \mathrm{E}-06$ & 0.1 & 0.007 & $7.42 \mathrm{E}-06$ & 0.03 & 0.025 \\
Chlorpyrifos & $7.42 \mathrm{E}-06$ & 0.1 & 0.007 & $7.42 \mathrm{E}-06$ & 0.01 & 0.074 \\
Diazinon & $2.05 \mathrm{E}-04$ & 0.03 & $\mathbf{0 . 6 8 2}$ & $1.59 \mathrm{E}-04$ & 0.005 & $\mathbf{3 . 1 7 4}$ \\
Dimethoate & $3.66 \mathrm{E}-04$ & 0.02 & $\mathbf{1 . 8 3 2}$ & $2.09 \mathrm{E}-04$ & 0.002 & $\mathbf{1 0 . 4 6}$ \\
Fenitrothion & $7.42 \mathrm{E}-06$ & 0.04 & 0.019 & $7.42 \mathrm{E}-06$ & 0.005 & 0.148 \\
Malathion & $7.42 \mathrm{E}-06$ & 0.3 & 0.002 & $7.42 \mathrm{E}-06$ & 0.03 & 0.025 \\
Quinalphos & $/$ & $/$ & $/$ & $/$ & $/$ & $/$
\end{tabular}

ARfD and ADI were adopted from JMPR database. The symbol of "/" represented that there was no authorized value for ARfD/ $\mathrm{ADI}$, and the corresponding risk index could not be computed.

The country bean consumption value is based on their commended dietary intake per day for non-leafy vegetables of $89 \mathrm{~g} / \mathrm{day}$ (data from FAO/WHO Dietary Guide (FAO/WHO, 2003).

When the detected residues in the sample were below the LOQ; for these values, data were treated with LOQ/2 (Yuan et al., 2014).

Table 5. The short-term and long-term risks due to the average daily intake of organophosphorus pesticides through bitter gourd consumption in Cumilla, Bangladesh

\begin{tabular}{ccccccc}
\hline \multirow{2}{*}{ Pesticide } & \multicolumn{3}{c}{ Short-term risk } & \multicolumn{3}{c}{ Long-term risk } \\
\cline { 2 - 7 } & ESTI (mg/kg/day) & ARfD $(\mathrm{mg} / \mathrm{kg} / \mathrm{bw} /$ day $)$ & $\mathrm{aHI}(\%)$ & EDI $(\mathrm{mg} / \mathrm{kg} / \mathrm{day})$ & ADI $(\mathrm{mg} / \mathrm{kg} / \mathrm{day})$ & $\mathrm{HQ}$ \\
\hline Acephate & $7.42 \mathrm{E}-06$ & 0.1 & 0.007 & $7.42 \mathrm{E}-06$ & 0.03 & 0.025 \\
Chlorpyrifos & $8.31 \mathrm{E}-05$ & 0.1 & 0.083 & $8.31 \mathrm{E}-05$ & 0.01 & $\mathbf{0 . 8 3 1}$ \\
Diazinon & $1.68 \mathrm{E}-04$ & 0.03 & $\mathbf{0 . 5 5 9}$ & $1.44 \mathrm{E}-04$ & 0.005 & $\mathbf{2 . 8 7 8}$ \\
Dimethoate & $4.75 \mathrm{E}-05$ & 0.02 & $\mathbf{0 . 2 3 7}$ & $4.75 \mathrm{E}-05$ & 0.002 & $\mathbf{2 . 3 7 3}$ \\
Fenitrothion & $7.42 \mathrm{E}-06$ & 0.04 & 0.019 & $7.42 \mathrm{E}-06$ & 0.005 & 0.148 \\
Malathion & $7.42 \mathrm{E}-06$ & 0.3 & 0.002 & $7.42 \mathrm{E}-06$ & 0.03 & 0.025 \\
Quinalphos & $/$ & $/$ & $/$ & $/$ & $/$ & $/$
\end{tabular}

ARfD and ADI were adopted from JMPR database. The symbol of “/” represented that there was no authorized value for ARfD/ ADI, and the corresponding risk index could not be computed.

The country bean consumption value is based on their commended dietary intake per day for non-leafy vegetables of 89 g/day (data from FAO/WHO Dietary Guide (FAO/WHO, 2003).

When the detected residues in the sample were below the LOQ; for these values, data were treated with LOQ/2 (Yuan et al., 2014). 
exposure to the organophosphorus pesticides via bitter gourd consumption. However, in the long-term risk assessment, the risk indexes (HQs) were also much lower than $100 \%$. So, the health risk from organophosphorus pesticide residues in bitter gourd was relatively smaller, which indirectly reflect the lower residue level of pesticides in bitter gourd. Health risk estimation revealed that dimethoate, diazinon and chlorpyrifos, though exceeded their MRLs in the country bean and bitter gourd, could not pose potential toxicity to the consumer. The acute and chronic risk index values showed that there was no health risk for consumers of Cumilla, Bangladesh, due to the intake of organophosphorus pesticide residues on these vegetables. Pesticide concentrations in vegetable products are known to be reduced by different home processing like washing, peeling, or cooking (Soliman, 2001; Wu et al., 2007; Ling et al., 2011; Yang et al., 2012; Huan et al., 2015). So, future studies should consider processing factors to compensate for reducing or removing pesticides.

\section{Conclusion}

This study found that country bean and bitter gourd contained organophosphorus pesticide residues in $16.25 \%$ of all samples collected from the major vegetable market of Cumilla district of Bangladesh. It was found that all detected samples exceeded the MRLs set by the EU. However, the short-term health risk or acute health indices (aHI) of those contaminated samples poses a negligible health risk for the consumer but chronic risk is considerably significant especially for dimethoate and diazinon. A modern traceability system can help to identify the source of contamination. Therefore, the observed levels of pesticide residues in the country bean and bitter gourd of Cumilla, Bangladesh do not pose a serious risk to consumers but pesticide contamination in vegetables may give rise to concern.

\section{Conflict of interest}

The authors declare no conflicts of interest.

\section{Acknowledgments}

We are very much grateful to Sher-e-Bangla Agricultural University Research System (SAURES) and Ministry of Science and Technology for providing financial support and also thankful Md. Kamal Hossain, Laboratory Technician in the pesticide analytical laboratory of Entomology Division, Bangladesh Agricultural Research Institute (BARI) for his cooperation to analyze the samples.

\section{References}

Ahmed, M.S., Begum, A., Rahman, M.A., Akon, M.W. and Chowdhury, M.A.Z. (2017). Extent of Insecticide Residue Load in Vegetables Grown under Conventional Farming in Bangladesh. The Agriculturists, 14(2), 38-47. https://doi.org/10.3329/ agric.v14i2.31346

Akram, M.W., Rahman, M. and Ali, R. (2010). Evaluation of Some Management Practices for the Suppression of Cucurbit Fruit Fly in Bitter Gourd. Journal of the Bangladesh Agricultural University, 8 (1), 23-28. https://doi.org/10.3329/jbau.v8i1.6393.

Aktar, M.A., Khatun, R. and Prodhan, M.D.H. (2017). Determination of Pesticide Residues in Eggplant Using Modified QuEChERS Extraction and Gas Chromatography. International Journal of Agronomy and Agricultural Research, 11(2), 22-31.

Bello-Ramírez, A.M., Carreón-Garabito, B.Y. and NavaOcampo, A.A. (2000). A Theoretical Approach to the Mechanism of Biological Oxidation of Organophosphorus Pesticides. Toxicology, 149(2-3), 63-68. https://doi.org/10.1016/S0300-483X(00) 00222-5.

Chowdhury, M.T.I., Razzaque, M.A. and Khan, M.S.I. (2011). Chlorinated Pesticide Residue Status in Tomato, Potato and Carrot. Journal of Experimental Sciences, 2(1), 1-5.

Corbett, J.R. (1974). The Biochemical Mode of Action of Pesticides. London, United Kingdom: Academic Press.

Dasgupta, S., Meisner, C. and Huq, M. (2007). A Pinch or a Pint? Evidence of Pesticide Overuse in Bangladesh. Journal of Agricultural Economics, 58 (1), 91-114. https://doi.org/10.1111/j.14779552.2007.00083.x.

Espinoza-Navarro, O., Ponce-LaRosa, C. and BustosObregón, E. (2017). Organophosphorous Pesticides: Their Effects on Biosentinel Species and Humans. Control and Application in Chile. International Journal of Morphology, 35(3), 1069-1074. https:// doi.org/10.4067/S0717-95022017000300041.

Eto, M. and Zweig, G. (2018). Organophosphorus Pesticides. $1^{\text {st }}$ ed. Boca Raton, USA: CRC Press. https://doi.org/10.1201/9781351075305.

European Commission. (2005). Maximum Residue Levels of Pesticides in or on Food and Feed of Plant and Animal Origin. EC-396/2005. Brussel, Belgium.

FAO/WHO. (2003). Diet, Nutrition and the Prevention of Chronic Diseases. Report of a Joint FAO/WHO Expert Consultation. Geneva, Rome: FAO.

González-Curbelo, M.A., Herrera-Herrera, A.V., RaveloPérez, L.M. and Hernández-Borges, J. (2012). 
Sample-Preparation Methods for Pesticide-Residue Analysis in Cereals and Derivatives. TrAC Trends in Analytical Chemistry, 38, 32-51. https:// doi.org/10.1016/j.trac.2012.04.010.

Grube, A., Donaldson, D., Kiely, T. and Wu, L. (2011). Pesticides Industry Sales and Usage: 2006 and 2007 Market Estimates. Washington DC, USA: USEPA. https://www.epa.gov/sites/production/files/2015-10/ documents/market_estimates2007.pdf.

Gupta, R.C. (2005). Toxicology of Organophosphate and Carbamate Compounds. USA: Academic Press. https://doi.org/10.1016/B978-0-12-088523-7.X50005.

Hasan, R., Prodan, M.D.H., Rahman, S.M., Khanom, R. and Ullah, A. (2017). Determination of Organophosphorus Insecticide Residues in Country Bean Collected from Different Markets of Dhaka. Journal of Environmental and Analytical Toxicology, 7(4), 489. https://doi.org/10.4172/21610525.1000489 .

Hassani, S., Momtaz, S., Vakhshiteh, F., Maghsoudi, A.S., Ganjali, M.R., Norouzi, P. and Abdollahi, M. (2017). Biosensors and Their Applications in Detection of Organophosphorus Pesticides in the Environment. Archives of Toxicology, 91(1), 109130. https://doi.org/10.1007/s00204-016-1875-8.

Herrera-Herrera, A.V., González-Sálamo, J., SocasRodríguez, B. and Hernández-Borges, J. (2019). Organophosphorus Pesticides (OPPs) in Bread and Flours. In Preedy, V.R. and Watson, R.R. (Eds.) Flour and Breads and their Fortification in Health and Disease Prevention. $2^{\text {nd }}$ ed., p. 53-70. USA: Academic Press. https://doi.org/10.1016/B978-0-12814639-2.00005-8.

Hossain, M.S., Farkhruddin, A.N.M., Chowdhury, M.A.Z., Rahman, M.A. and Alam, M.K. (2015). Health Risk Assessment of Selected Pesticide Residues in Locally Produced Vegetables of Bangladesh. International Food Research Journal, 22(1), 110-115.

Huan, Z., Xu, Z., Jiang, W., Chen, Z. and Luo, J. (2015). Effect of Chinese Traditional Cooking on Eight Pesticides Residue during Cowpea Processing. Food Chemistry, 170, 118-122. https://doi.org/10.1016/ j.foodchem.2014.08.052.

Islam, M.S., Prodhan, M.D.H. and Uddin, M.K. (2019). Analysis of the Pesticide Residues in Bitter Gourd Using Modified QuEChERS Extraction Coupled with Gas Chromatography. Asia Pacific Environmental and Occupational Health Journal, 3 (5), 6-15.

Islam, M.W., Dastogeer, K.M.G., Hamim, I., Prodhan,
M.D.H. and Ashrafuzzaman, M. (2014). Detection and Quantification of Pesticide Residues in Selected Vegetables of Bangladesh. Journal of Phytopathology and pest Management, 1(2), 17-30.

Islam, S., Afrin, N., Hossain, M.S., Nahar, N., Mosihuzzaman, M. and Mamun, M.I.R. (2009). Analysis of Some Pesticide Residues in Cauliflower by High Performance Liquid Chromatography. American Journal of Environmental Sciences, 5(3), 325-329.

JMPR. (2004). Pesticide Residues in Food 2004: Toxicological Evaluations. Rome, Italy: JMPR.

JMPR. (2006). Pesticide Residues in Food 2006: Joint FAO/WHO Meeting on Pesticide Residues. Rome, Italy: JMPR

Joshi, S.C. and Sharma, P. (2011). Male Reproductive Toxicity of Organophosphorous Compounds: A Review. Toxicological and Environmental Chemistry, 93(7), 1486-1507. https:// doi.org/10.1080/02772248.2011.581874.

Kwong, T.C. (2002). Organophosphate Pesticides: Biochemistry and Clinical Toxicology. Therapeutic Drug Monitoring, 24(1), 144-149. https:// doi.org/10.1097/00007691-200202000-00022.

Ling, Y., Wang, H., Yong, W., Zhang, F., Sun, L., Yang, M. L., Wu, Y.N. and Chu, X.G. (2011). The Effects of Washing and Cooking on Chlorpyrifos and Its Toxic Metabolites in Vegetables. Food Control, 22 (1), 54-58. https://doi.org/10.1016/ j.foodcont.2010.06.009.

Monoarul Haque, M., Amirul Hassan, M., Islam, K., Bhuiyan, M.R., Shahi, M.S.J.R. and Lipi, R.P. (2014). Diet Intake Pattern and Nutritional Status of Rural Population in Bangladesh. Chattagram Maa-O -Shishu Hospital Medical College Journal, 13(2), 51 -54. https://doi.org/10.3329/cmoshmcj.v13i2.21065.

Prodhan, M.D.H., Papadakis, E.N. and PapadopoulouMourkidou, E. (2015). Determination of Multiple Pesticide Residues in Eggplant with Liquid Chromatography-Mass Spectrometry. Food Analytical Methods, 8(1), 229-235. https:// doi.org/10.1007/s12161-014-9898-3.

Quasem, M.A. (2003). Exports of Fresh Horticultural Crops from Bangladesh: Problems and Prospects. Dhaka, Bangladesh: Bangladesh Institute of Development Studies.

Rahaman, M.A., Jahan, M., Islam, K.S. and Alam, S.N. (2016). Efficacy of three biopesticides against cucurbit fruit fly, Bactrocera cucurbitae Coquillett (Diptera: Tephritidae) and yield of bitter gourd. Journal of Sylhet Agricultural University, 3(2), 197202. 
Rahaman, M.A., Prodhan, M.D.H. and Maula, M.A.K.M. (2008). Effect of botanical and synthetic pesticides in controlling epilachna. International Journal of Sustainable Crop Products, 3(5), 23-26.

Ramulu, S. (2020). Chemistry of Insecticides and Fungicides. $3^{\text {rd }}$ ed. India: Scientific Publishers.

Soliman, K.M. (2001). Changes in Concentration of Pesticide Residues in Potatoes during Washing and Home Preparation. Food and Chemical Toxicology, 39(8), 887-891. https://doi.org/10.1016/S0278-6915 (00)00177-0.

Sultana, P. and Nakagoshi, N. (2001). An Analysis of Pesticide Use for Rice Pest Management in Bangladesh. Journal of International Development and Cooperation, 8(1), 107-126.

Wu, J., Luan, T., Lan, C., Hung Lo, T.W. and Chan, G.Y.S. (2007). Removal of Residual Pesticides on Vegetable Using Ozonated Water. Food Control, 18 (5), 466-472. https://doi.org/10.1016/ j.foodcont.2005.12.011.

Yang, A., Park, J.H., Abd El-Aty, A.M., Choi, J.H., Oh, J.H., Do, J.A., Kwon, K., Shim, K.H., Choi, O.J. and Shim, J.H. (2012). Synergistic Effect of Washing and Cooking on the Removal of Multi-Classes of Pesticides from Various Food Samples. Food Control, 28(1), 99-105. https://doi.org/10.1016/ j.foodcont.2012.04.018.

Yuan, Y., Chen, C., Zheng, C., Wang, X., Yang, G., Wang, Q. and Zhang, Z. (2014). Residue of Chlorpyrifos and Cypermethrin in Vegetables and Probabilistic Exposure Assessment for Consumers in Zhejiang Province, China. Food Control, 36(1), 6368. https://doi.org/10.1016/j.foodcont.2013.08.008. 